\title{
Datura stramonium (Solanaceae): Antioxidant and Antimicrobial Potentials
}

\author{
Falah Saleh Mohammed ${ }^{1, a,}$, Eylem Kına ${ }^{2, b}$, Mustafa Sevindik ${ }^{3, c}$, Muhittin Dogan²,d $^{2,}$ Mustafa Pehlivan $^{4, e}$ \\ ${ }^{1}$ Department of Biology, Faculty of Science, Zakho University, Zakho, Iraq \\ ${ }^{2}$ Department of Biology, Faculty of Science and Literature, Gaziantep University, 27410 Gaziantep, Turkey \\ ${ }^{3}$ Osmaniye Korkut Ata University, Bahçe Vocational High School, 80500 Osmaniye, Turkey \\ ${ }^{4}$ Nurdağ Vocational School, Gaziantep University, 27840 Nurda $\breve{g}_{l} /$ Gaziantep, Turkey \\ *Corresponding author
}

A R T I C L E I N F O A B S T R A C T

\section{Research Article}

Received : 21/02/2021

Accepted : 27/03/2021
Many people in different parts of the world benefit from alternative medicine in the treatment and prevention of diseases. Plants are among the important natural materials used in alternative medicine. In this study, the antioxidant and antimicrobial potential of Datura stramonium L. was determined. Ethanol extracts of the plant's flower parts were obtained in the soxhlet device. The antioxidant and oxidant potential of the plant extract was determined using Rel Assay TAS and TOS kits. Antimicrobial activity was tested by the agar dilution method. The TAS value of the plant extract was $7.559 \pm 0.224 \mathrm{mmol} / \mathrm{L}$, the TOS value was $10.711 \pm 0.243 \mu \mathrm{mol} / \mathrm{L}$, and the OSI value was $0.142 \pm 0.002$. It was determined that the plant extract was effective against bacteria and fungus strains at $100-400 \mu \mathrm{g} / \mathrm{mL}$ concentration. As a result, it was determined in our study that $D$. stramonium can be a natural antioxidant and antimicrobial source.
Keywords:

Antioxidant

Antimicrobial

Datura

Jimsonweeds

Medicinal plant falah.sindy@uoz.edu.krd sevindik27@gmail.com mpehlivan27@hotmail.com
(iD) https://orcid.org/0000-0001-9083-1876 iD https://orcid.org/0000-0001-7223-2220

(i) https://orcid.org/0000-0002-8277-6085 b@eylem.kinaa@gmail.com doganm@gantep.edu.tr
iD https://orcid.org/0000-0003-4538-9737 https://orcid.org/0000-0001-5400-8065

\section{Introduction}

From past to present, many communities have benefited from alternative medicine in the treatment and prevention of diseases. Many different natural materials such as plants, mushrooms and animals are used in alternative medicine (Krupodorova and Sevindik, 2020; Salehi et al., 2020a). Especially plants contain the active ingredients of many drugs used against different diseases. Many studies have shown that plants have different biological activities. In these studies, it has been reported that herbs have different effects such as antioxidant, anticancer, antitumor, DNA protective, antiproliferative, anti-inflammatory, antimicrobial and antiallergic (Calixto et al., 2001; Schinella et al., 2002; Miliauskaset al., 2004; Makchuchit et al., 2017; Lichota and Gwozdzinski, 2018; Khanet al., 2019; Salehi et al., 2019; Salehi et al., 2020b). In this study, the antioxidant and antimicrobial activity of Datura stramonium L. was determined.

D. stramonium from the Solanaceae family is known as prickly apple, jimsonweed or devil's snare. Although it originates in Central America, it is distributed in different parts of the world. It is very common, especially in temperate climates. It spreads naturally in hot and temperate regions of the world, along roadsides and in manure-rich animal shelters. It is found as a weed in dumpsites and wasteland in Europe (Lovett et al., 1981). And it can be toxic to animals that consume it. The seeds of the plant can remain passive underground for many years and can sprout when the soil deteriorates. $D$. stramonium is frequently used in alternative medicine for the treatment of many different ailments. It is used in alternative medicine, especially due to its analgesic and anesthetic properties. It is also used in the treatment of epilepsy and asthma (Lewis, 1784; Culpeper, 1995; Pennacchio et al., 2010). However, the plant has been reported to have halcinogenic properties. It causes many mental and physical effects. It can also cause a profound and prolonged disorientation with potentially fatal consequences. It contains tropane alkaloids, which cause these effects and can be highly toxic. Datura species contain tropane alkaloids such as atropine, hyoscyamine and scopolamine, which are called delirants or anticholinergics, in all plant parts. The risk of overdose by uninformed consumers is quite high, and hospitalization for recreational users is quite high due to its psychoactive properties (Barceloux, 2008; Glatstein et al., 2016). 


\section{Materials and Methods}

D. stramonium samples were collected from Turkey (Gaziantep/Şahinbey). Flora of Turkey and the East Aegean Islands, Volume 6 was used in the identification of the plant (Davis, 1965). Flower parts of the plant were dried in a breathable environment. $30 \mathrm{~g}$ of the dry samples were weighed and pulverized in a mechanical shredder. Powder samples were extracted at $50{ }^{\circ} \mathrm{C}$ with $200 \mathrm{~mL}$ of EtOH during approximately 6 hours (Gerhardt EV 14). The solvent was removed in the concentrator after Soxhlet apparatus (Heidolph Laborota 4000 Rotary Evaporator).

\section{Antimicrobial Activity Studies}

The effects of the EtOH extract of the flower parts of the plant against microorganisms were determined using the agar dilution method. The concentrations of the extracts were adjusted in the range of $6.25-800 \mu \mathrm{g} / \mathrm{mL}$. Extract concentrations were adjusted with distilled water. The lowest concentrations of the extracts preventing the growth of bacteria and fungi were determined in the study (CLSI, 2012; EUCAST, 2014; EUCAST, 2015). Test bacteria were used as Pseudomonas aeruginosa ATCC 27853, Acinetobacter baumannii ATCC 19606, Staphylococcus aureus ATCC 29213, S. aureus MRSA ATCC 43300, Enterococcus faecalis ATCC 29212 and Escherichia coli ATCC 25922. Test fungi Candida albicans ATCC 10231, C. krusei ATCC 34135 and C. glabrata ATCC 90030 were used. Bacteria pre-culturing was done in Muller Hinton Broth medium and Amikacin, Ampicillin and Ciprofloxacin were used as reference drugs. The preculturing of the fungi was done in RPMI 1640 Broth medium and Fluconazole and Amphotericin B were used as reference drugs (Bauer et al., 1966; Hindler et al., 1992; Matuschek et al., 2014).

\section{Antioxidant Tests}

The antioxidant status of the plant extract was measured using the Rel Assay TAS kit and Trolox was used as the calibrator (Erel, 2004). In addition, oxidant status was determined using the TOS kit and hydrogen peroxide was used as a calibrator (Erel, 2005). The oxidative stress index (OSI, $\mu$ mol $\mathrm{H}_{2} \mathrm{O}_{2}$ equiv./L) was found by equalizing the unit of the TOS value and the unit of the TAS (mmol Trolox equiv./L) value. The following formula was used to determine the OSI value (Sevindik, 2019).

$$
\text { OSI }(\mathrm{AU})=\mathrm{TOS} /(\mathrm{OSI} \times 10) \times 10
$$

\section{Results and Discussion}

\section{Antimicrobial potential}

In recent years, the discovery of new antibiotics has been inevitable due to the resistance of microorganisms to antibiotics. In addition, due to the possible side effects of synthetic antibiotics, interest in natural antimicrobial products is increasing (Zazharskyi et al., 2019; Sevindik, 2020). In this study, the effect of the EtOH extract of $D$. stramonium against test bacteria and fungi was investigated. The results obtained are shown in Table 1.
Table 1. Antibacterial and antifungal activities of $D$. stramonium

\begin{tabular}{l|l}
\hline \multicolumn{1}{c|}{ Microorganisms } & EtOH \\
\hline S. aureus & 100 \\
S. aureus MRSA & 100 \\
E. faecalis & 200 \\
E. coli & 100 \\
P. aeruginosa & 100 \\
A. baumannii & 400 \\
C. albicans & 200 \\
C. glabrata & 200 \\
C. krusei & 200 \\
\hline
\end{tabular}

*The MIC values are presented in units of $\mu \mathrm{g} / \mathrm{mL}$.

It was previously reported that the methanol extract of $D$. stramonium is effective against Bacillus thuringiensis, $B$. subtilis Pseudomonas aeruginosa, Agrobacterium tumefaciens, Escherichia coli, Enterococous faecalis, Staphylococcus aureus and Klebsiella pneumoniae (Eftekhar et al., 2005; Deshmukh et al., 2015). In addition, benzene, chloroform and ethanol extracts of $D$. stramonium were reported to be effective against Enterobacter, Klebsiella pneumoniae, Escherichia coli, Staphylococcus aureus, Pseudomonas aeruginosa and Micrococcus luteus (Gul et al., 2012). Ethanol, methanol, acetone and chloroform extracts of $D$. stramonium have been reported to be effective against Escherichia coli, Staphylococcus aureus, Streptococcus pneumoniae and their clinical isolates (Baynesagne et al., 2017). In our study, it was determined that the ethanol extract of $D$. stramonium was effective against A. baumannii at $400 \mu \mathrm{g} / \mathrm{mL}$ concentration. In addition, it was determined that the plant extract was effective against $E$. faecalis, $C$. albicans, $C$. glabrata and $C$. krusei at $200 \mu \mathrm{g} / \mathrm{mL}$ concentration. In addition, it was determined that it was effective against $S$. aureus, $S$. aureus MRSA, E. coli and $P$. aeruginosa at $100 \mu \mathrm{g} / \mathrm{mL}$ concentration. As a result, in our study, it was seen that $D$. stramonium has antimicrobial activity against test bacteria and fungi. In this context, it was determined that the flower parts of the plant could be a natural antimicrobial agent.

\section{Antioxidant and Oxidant Status}

Plant based antioxidants are widely used to prevent oxidative degradation. Oxidative degradation occurs in living organisms with the accumulation and increase of levels of oxidant compounds produced as a result of metabolic activities (Adebiyi et al., 2017). In such cases, the antioxidant defense system can prevent or suppress oxidative damage in the living organism. In cases where endogenous antioxidants are insufficient, supplemental antioxidants can be used (Arnao et al., 1999; Xiang et al., 2019). In our study, the utilization potential of $D$. stramonium as a natural antioxidant agent was determined. The findings obtained are shown in Table 2.

Table 1. Antioxidant and oxidant status of D. stramonium

\begin{tabular}{l|l}
\hline \multicolumn{1}{c|}{ Parameters } & \multicolumn{1}{c}{ D. stramonium } \\
\hline TAS & $7.559 \pm 0.224$ \\
TOS & $10.711 \pm 0.243$ \\
OSI & $0.142 \pm 0.002$ \\
\hline
\end{tabular}

Values are presented as mean \pm SD 
In previous studies, it was reported that petroleum ether, benzene, solvent ether, chloroform, acetone, ethanol and methanol extracts of $D$. stramonium had antioxidant potential with different methods (DPPH radical scavenging assay, Superoxide radical scavenging assay, ABTS + radical cation scavenging assay, Hydroxyl $(\mathrm{OH})$ radical scavenging assay, Nitric oxide (NO) radical scavenging assay, Ferric $(\mathrm{Fe} 3+)$ reducing power assay, Phosphomolybdenum reduction assay) (Kumar et al., 2008; Sreenivasa et al., 2012; Iqbal et al. , 2017; Belayneh et al., 2019). In our study, the antioxidant potential of EtoH extract of D. stramonium was determined for the first time using TAS and TOS kits. In TAS and TOS studies previously performed on different plant species, TAS values of Mentha longifolia subsp. longifolia, Allium calocephalum, Ferulago platycarpa, Gundellia tournefortii, Rhus coriaria var. zebaria, Rumex crispus and Scorzonera papposa were reported as $3.628,5.853,5.688$, $6.831,7.342,6.758$ and $5.314 \mathrm{mmol} / \mathrm{L}$, respectively. The TOS values were reported as 4.046, 16.288, 15.552, 3.712, $5.170,5.802$ and 24.199 . OSI values were reported as $0.112,0.278,0.273,0.054,0.071,0.086$ and 0.473 (Sevindik et al., 2017; Mohammed et al., 2018; Daştan et al., 2019; Mohammed et al., 2019; Saraç et al., 2019; Mohammed et al., 2020a; Mohammed et al., 2020b). Compared to these studies, it was determined that the TAS value of $D$. stramonium was higher than $M$. longifolia subsp. longifolia, A. calocephalum, F. platycarpa, $G$. tournefortii, $R$. coriaria var. zebaria, $R$. crispus and $S$. papposa. TAS value shows the whole of the antioxidant active compounds in the plant. In this context, it has been observed that the antioxidant potential of $D$. stramonium is high. As a result, it was determined that the plant has significant antioxidant activity.

It was also determined that the TOS value of $D$. stramonium was higher than $M$. longifolia subsp. longifolia, G. tournefortii, $R$. coriaria var. zebaria and $R$. crispus and lower than A. calocephalum, F. platycarpa and $S$. papposa. The TOS value indicates the whole of oxidantfeatured compounds produced in the plant by environmental effects. In this context, it was determined that the TOS value of the plant was at normal levels. In addition, when the OSI value showing the suppression of oxidant compounds by endogenous antioxidants is examined, it was determined that $D$. stramonium had higher values than $M$. longifolia subsp. longifolia, $G$. tournefortii, R. coriaria var. zebaria and $R$. crispus and lower than A. calocephalum, $F$. platycarpa and $S$. papposa. In this context, it was seen that the endogenous antioxidant potential of the plant suppressed endogenous oxidant compounds well. As a result, it was determined that the plant could be a natural source of antioxidants.

\section{Conclusion}

In this study, the antioxidant and oxidant status and antimicrobial activity of $D$. stramonium were determined. It was determined that the plant's antioxidant potential was high. In addition, oxidant levels were found to be at normal levels. In addition, it was found to be effective against bacteria and fungus strains. As a result, it was determined that the plant has antioxidant and antimicrobial potentials.

\section{References}

Adebiyi OE, Olayemi FO, Ning-Hua T, Guang-Zhi Z. 2017. In vitro antioxidant activity, total phenolic and flavonoid contents of ethanol extract of stem and leaf of Grewia carpinifolia. Beni-Suef University Journal of Basic and Applied Sciences, 6(1): 10-14.

Arnao MB, Cano A, Acosta M. 1999. Methods to measure the antioxidant activity in plant material. A comparative discussion. Free Radical Research, 31(sup1): 89-96.

Barceloux DG. 2008. Medical toxicology of natural substances: foods, fungi, medicinal herbs, plants, and venomous animals. John Wiley \& Sons.

Bauer AW, Kirby WM, Sherris JC, Turck M. 1966. Antibiotic susceptibility testing by a standardized single disk method, Am J Clin Pathol, 45: 493-96.

Baynesagne S, Berhane N, Sendeku W, Ai L. 2017. Antibacterial activity of Datura stramonium against standard and clinical isolate pathogenic microorganisms. Journal of medicinal plants research, 11(31): 501-506.

Belayneh YM, Birhanu Z, Birru EM, Getenet G. 2019. Evaluation of in vivo antidiabetic, antidyslipidemic, and in vitro antioxidant activities of hydromethanolic root extract of Datura stramonium L. (Solanaceae). Journal of experimental Pharmacology, 11: 29.

Calixto JB, Scheidt C, Otuki M, Santos AR. 2001. Biological activity of plant extracts: novel analgesic drugs. Expert opinion on emerging drugs, 6(2): 261-279.

CLSI (The Clinical and Laboratory Standards Institute). 2012. Antimicrobial Susceptibility Testing of Anaerobic Bacteria; Approved Standard-Eighth Edition (M11-A8).

Culpeper N. 1995. Culpeper's complete herbal: A book of natural remedies for ancient ills. Wordsworth Editions.

Daştan SD, Durukan H, Demirbaş A, Dönmez E. 2019. Bioactivity and Therapeutic Properties of Evelik (Rumex crispus), A Naturally Growing and Edible Plant in Sivas Province. Turkish Journal of Agriculture - Food Science and Technology, 7(sp2): 67-71.

Davis PH. 1965. Flora of Turkey and the East Aegean Islands, Volume 6, Edinburgh University Press pp. 451

Deshmukh AS, Shelke PD, Palekar KS, Pawar SD, Hs S. 2015. Antimicrobial Investigation of Datura stramonium Leaf Extract against different Microorganisms. IOSR Journal of Environmental Science, Toxicology and Food Technology, 9(9):17-19.

Eftekhar F, Yousefzadi M, Tafakori V. 2005. Antimicrobial activity of Datura innoxia and Datura stramonium. Fitoterapia, 76(1): 118-120.

Erel O. 2004. A new automated colorimetric method for measuring total oxidant status. Clin biochem, 38(12): 1103-1111.

Erel O. 2005. A novel automated direct measurement method for total antioxidant capacity using a new generation, more stable ABTS radical cation, Clin biochem, 37(4): 277- 285.

EUCAST (European Committee on Antimicrobial Susceptibility Testing). 2014. Breakpoint tables Fungal isolate for interpretation of MICs. Version 7.0.

EUCAST (European Committee on Antimicrobial Susceptibility Testing). 2015. Breakpoint tables for Bacteria interpretation of MICs and zone diameters, Version 5.0.

Glatstein M, Alabdulrazzaq F, Scolnik D. 2016. Belladonna alkaloid intoxication: the 10-year experience of a large tertiary care pediatric hospital. American journal of therapeutics, 23(1): e74-e77.

Gul H, Qaisrani RN, Khan MA, Hassan S, Younis N. 2012. Antibacterial and antifungal activity of different extracts of Datura stramonium (branches and leaves sample). Journal of Biotechnology and Pharmaceutical Research, 3(9): 141-148. 
Hindler J, Hochstein L, Howell A. 1992. Preparation of routine media and reagents used in antimicrobial susceptibility testing. Part 1. McFarland standards, p. 5.19.1-5.19.6. In H. D. Isenberg (ed) Clinical microbiology procedures handbook, vol. 1 . American Society for Microbiology, Washington, D.C.

Iqbal S, Sivaraj C, Gunasekaran K. 2017. Antioxidant and Anticancer Activities of Methanol Extract of Seeds of Datura stramonium 1. Free Radicals and Antioxidants, 7(2): 184-189.

Khan AK, Singh PD, Reese PB, Howden J, Thomas TT. 2019. Investigation of the anti-inflammatory and the analgesic effects of the extracts from Smilax ornata Lem. (Jamaican sarsaparilla) plant. Journal of ethnopharmacology, 240: 111830

Krupodorova T, Sevindik M. 2020. Antioxidant potential and some mineral contents of wild edible mushroom Ramaria stricta. AgroLife Sci J, 9: 186-191.

Kumar PS, Sucheta S, Deepa VS, Selvamani P, Latha S. 2008. Antioxidant activity in some selected Indian medicinal plants. African Journal of Biotechnology, 7(12): 1826-1828

Lewis W. 1784. An Experimental History of the Materia Medica, Or of the Natural and Artificial Substances Made Use of in Medicine: Containing a Compendious View of Their Natural History, an Account of Their Pharmaceutic Properties and an Estimate of Their Medicinal Powers, J. Johnson \& R. Baldwin.

Lichota A, Gwozdzinski K. 2018. Anticancer activity of natural compounds from plant and marine environment. International journal of molecular sciences, 19(11): 3533.

Lovett JV, Levitt J, Duffield AM, Smith NG. 1981. Allelopathic potential of Datura stramonium L.(Thorn-apple). Weed Research, 21(3-4): 165-170.

Makchuchit S, Rattarom R, Itharat A. 2017. The anti-allergic and anti-inflammatory effects of Benjakul extract (a Thai traditional medicine), its constituent plants and its some pure constituents using in vitro experiments. Biomedicine \& Pharmacotherapy, 89: 1018-1026.

Matuschek E, Brown DF, Kahlmeter G. 2017. Development of the EUCAST disk diffusion antimicrobial susceptibility testing method and its implementation in routine microbiology laboratories, Clin Microbiol Infect, 20: 255266.

Miliauskas G, Venskutonis PR, Van Beek TA. 2004. Screening of radical scavenging activity of some medicinal and aromatic plant extracts. Food chemistry, 85(2): 231-237.

Mohammed FS, Akgul H, Sevindik M, Khaled BMT. 2018. Phenolic content and biological activities of Rhus coriaria var. zebaria. Fresen Environ Bull, 27(8): 5694-5702.

Mohammed FS, Günal S, Pehlivan M, Doğan M, Sevindik M, Akgül H. 2020. Phenolic content, antioxidant and antimicrobial potential of endemic Ferulago platycarpa. Gazi Univ J Sci, 33(4): 670-677.

Mohammed FS, Günal S, Şabik AE, Akgül H, Sevindik M. 2020. Antioxidant and Antimicrobial activity of Scorzonera papposa collected from Iraq and Turkey. Kahramanmaraş Sütçü İmam Univ Doğa Bilim Derg, 23(5): 1114-1118.
Mohammed FS, Karakaş M, Akgül H, Sevindik M. 2019. Medicinal properties of Allium calocephalum collected from Gara Mountain (Iraq), Fresen Environ Bull, 2019, 28(10): 7419-7426.

Pennacchio M, Jefferson L, Havens K. 2010. Uses and abuses of plant-derived smoke: Its ethnobotany as hallucinogen, perfume, incense, and medicine. Oxford University Press.

Salehi B, Gültekin-Özgüven M, Kirkin C, Özçelik B, MoraisBraga MFB, Carneiro JNP, Bezerra CF, da Silva TG, Coutinho HDM, Amina B, Armstrong L, Selamoglu Z, Sevindik M, Yousaf Z, Sharifi-Rad J, Muddathir AM, Devkota HP, Martorell M, Jugran AK, Cho W, Martins N. 2020. Antioxidant, antimicrobial, and anticancer effects of anacardium plants: an ethnopharmacological perspective, Front Endocrinol, 11: 295.

Salehi B, Gültekin-Özgüven M, Kırkın C, Özçelik B, MoraisBraga MFB, Carneiro JNP, Bezerra CF, da Silva TG, Coutinho HDM, Amina B, Armstrong L, Selamoglu Z, Sevindik M, Yousaf Z, Sharifi-Rad J, Muddathir AM, Devkota HP, Martorell M, Jugran AK, Martins N, Cho WC. 2019. Anacardium plants: chemical, nutritional composition and biotechnological applications, Biomolecules, 9(9): 465.

Salehi B, Selamoglu Z, Sevindik M, Fahmy NM, Al-Sayed E, ElShazly M, Csupor-Löffler B, Csupor D, Yazdi DE, SharifiRad J, Arserim-Uçar DK, Arserim EH, Karazhan N, Jahani A, Dey A, Azadi H, Vakili SA, Sharopov F, Martins N, Büsselberg D, Büsselberg D. 2020. Achillea spp.: A comprehensive review on its ethnobotany, phytochemistry, phytopharmacology and industrial applications, Mol Cell Biol, 66(4): 78-103.

Saraç H, Demirbaş A, Daştan SD, Ataş M, Çevik Ö, Eruygur N. 2019. Evaluation of Nutrients and Biological Activities of Kenger (Gundellia tournefortii L.) Seeds Cultivated in Sivas Province. Turkish Journal of Agriculture - Food Science and Technology, 7(sp2): 52-58.

Schinella GR, Tournier HA, Prieto JM, De Buschiazzo PM, Rios JL. 2002. Antioxidant activity of anti-inflammatory plant extracts. Life sciences, 70(9): 1023-1033.

Sevindik M, Akgul H, Pehlivan M, Selamoglu Z. 2017. Determination of therapeutic potential of Mentha longifolia ssp. longifolia, Fresen Environ Bull, 26(7): 4757-4763.

Sevindik M. 2020. Antioxidant and antimicrobial capacity of Lactifluus rugatus and its antiproliferative activity on A549 cells, Indian J Tradit Knowl, 19(2): 423-427.

Sevindik M. 2019. The novel biological tests on various extracts of Cerioporus varius, Fresen Environ Bull, 28(5): 3713-3717.

Sreenivasa S, Vinay K, Mohan NR. 2012. Phytochemical analysis, antibacterial and antioxidant activity of leaf extract of Datura stramonium. International Journal of Science Research, 1(2): 83-86.

Xiang J, Apea-Bah FB, Ndolo VU, Katundu MC, Beta T. 2019. Profile of phenolic compounds and antioxidant activity of finger millet varieties. Food chemistry, 275: 361-368.

Zazharskyi VV, Davydenko P, Kulishenko O, Borovik IV, Brygadyrenko VV. 2019. Antimicrobial activity of 50 plant extracts. Biosystems Diversity, 27(2): 163-169. 